\title{
MicroRNA-1271 functions as a metastasis and epithelial-mesenchymal transition inhibitor in human HCC by targeting the PTP4A1/c-Src axis
}

\author{
CHAO LI $^{1 *}$, YEZHEN JIANG $^{1,2^{*}}$, RUNCHEN MIAO $^{1}, \mathrm{KAI} \mathrm{QU}^{1}$, JINGYAO ZHANG $^{1}$ and CHANG LIU ${ }^{1}$ \\ ${ }^{1}$ Department of Hepatobiliary Surgery, The First Affiliated Hospital of Xi'an Jiaotong University, Xi'an, Shaanxi 710061; \\ ${ }^{2}$ Department of Surgery, Xi'an Beihuan Hospital, Xi'an, Shaanxi 710032, P.R. China
}

Received October 9, 2017; Accepted November 30, 2017

DOI: $10.3892 /$ ijo.2017.4224

\begin{abstract}
MicroRNAs (miRNAs or miRs) have been shown to regulate hepatocellular carcinoma (HCC) metastasis. In the present study, we focused on the functions of miR-1271 in HCC metastasis. The downregulation of miR-1271 was found to be associated with to venous infiltration, an advanced TNM stage (III+IV stage) and a shorter survival time. Our in vitro and in vivo data demonstrated that miR-1271 prevented $\mathrm{HCC}$ cell migration and invasion, as well as the formation of lung metastatic clusters. In addition, miR-1271 was demonstrated to markedly inhibit the epithelial-mesenchymal transition (EMT) of HCC cells. Importantly, protein tyrosine phosphatase type IVA member 1 (PTP4A1) was identified as a direct downstream target of miR-1271 in HCC. Furthermore, we confirmed that the phosphorylation of c-Src at Tyr416 mediated by PTP4A1 was a potential anti-HCC mechanism of action of miR-1271. On the whole, our data indicate that miR-1271 inhibits HCC metastasis by targeting the PTP4A1/ $\mathrm{c}$-Src signaling pathway and may serve as a prospective cancer therapeutic target for HCC.
\end{abstract}

\section{Introduction}

The incidence and mortality associated with hepatocellular carcinoma (HCC) has increased in China, with $>400,000$ patients succumbing to the disease (1). HCC is becoming a major public health concern in China. Despite the use of modern therapies to improve the outcomes of patients with $\mathrm{HCC}$, distant metastasis and a high rate of recurrence restrict the 5-year survival rate (2). Therefore, the identification of

Correspondence to: Professor Chang Liu, Department of Hepatobiliary Surgery, The First Affiliated Hospital of Xi'an Jiaotong University, 277 Yanta West Road, Xi'an, Shaanxi 710061, P.R. China E-mail: liuchangdoctor@163.com

*Contributed equally

Key words: microRNA-1271, hepatocellular carcinoma, metastasis, epithelial-mesenchymal transition, protein tyrosine phosphatase type IVA member 1 novel anti-metastasis targets is urgently required to improve the prognosis of patients with HCC patients.

MicroRNAs (miRNAs or miRs) are a class of endogenous, highly conserved, short non-coding RNAs (3). They can bind to the 3'-untranslated region (3'-UTR) of mRNAs to decrease target gene expression (4). Various cellular processes have been reported to be regulated by different miRNAs in HCC. miR-218 has been shown to decrease tumor growth (5), miR-26a to inhibit metastasis (6) and miR-214 to prevent angiogenesis (7) in HCC. Moreover, certain miRNAs, including miR-155 (8), miR-137 (9) and miR-135a (10) have been shown to be associated with the recurrence of and poor survival in HCC. Hence, miRNAs have the potential to act as biomarkers of and therapeutic targets in HCC.

Mounting evidence indicates that miR-1271, a newly identified miRNA, is downregulated in endometrial cancer, prostate cancer and myeloma (11-13). The re-induction of miR-1271 has been shown to inhibit proliferation in ovarian cancer (14) and invasion in pancreatic cancer (15). However, Wang et al (16) reported a promoting effect of miR-1271 in the regulation of non-small cell lung cancer (NSCLC) proliferation and invasion by targeting HOXA5. Thus, these data seem to suggest that miR-1271 is a 'friend or foe' depending on the cancer type.

The pathophysiological program that transforms epithelial cell types into cells with a mesenchymal phenotype is identified as epithelial-mesenchymal transition (EMT) (17). EMT frequently occurs in cancer cells, particularly in metastatic cells. EMT contributes to the progression of cancers from the initial to the advanced grade, and is considered a critical mechanism for the migration, invasion and distinct metastasis of cancer cells (18).

In the present study, we examined the functions of miR-1271 in metastasis and EMT in HCC. We found that the downregulation of miR-1271 was a common occurrence in HCC tissues. The downregulation of miR-1271 was significantly associated with venous infiltration, an advanced TNM stage and a short survival time of patients with HCC. Furthermore, miR-1271 was demonstrated to significantly inhibit tumor migration, invasion and EMT, as well as the formation of lung metastatic clusters of HCC by targeting protein tyrosine phosphatase type IVA member 1 (PTP4A1). 


\section{Materials and methods}

Patients and cell lines. HCC tissues and matched non-tumor tissues were collected from 65 patients who underwent radical resection for HCC at the Department of Hepatobiliary Surgery, First Affiliated Hospital of Xi'an Jiaotong University (Xi'an, China) between January 2011 and January 2013. None of the patient received any anticancer therapy prior to surgery. All patients underwent a complete 3-year follow-up, unless they succumbed to the disease before the end of the 3 years. Written informed consents were obtained from all patients enrolled in this study. The use of clinical samples was approved by the Ethics Committee of First Affiliated Hospital of Xi'an Jiaotong University. In addition, 4 HCC cell lines (MHCC97H, SMMC7721, Huh-7 and Hep3B), and the human immortalized normal hepatocyte cell line (LO2) were obtained from the Shanghai Institute of Biochemistry and Cell Biology, Chinese Academy of Sciences (Shanghai, China) and maintained in our laboratory. The cells were cultured in Dulbecco's modified Eagle's liquid medium (DMEM; Gibco, Carlsbad, CA, USA) containing $10 \%$ fetal bovine serum (FBS; Gibco) with $1 \%$ v/c penicillin and streptomycin (Sigma-Aldrich, St. Louis, MO, USA) in a humidified air containing $5 \% \mathrm{CO}_{2}$ at $37^{\circ} \mathrm{C}$.

Cancer Genome Atlas dataset. Pre-analyzed The Cancer Genome Atlas (TCGA) mature microRNA RNA-Seq data of 271 HCC samples and 39 normal liver samples were collected from the UCSC Xena (http://xena.ucsc.edu).

Lentiviruses infection. miR-1271 vectors (miR-1271), negative control vectors (miR-ctrl), miR-1271 inhibitory vectors (anti-miR-1271) and negative control inhibitory vectors (antimiR-ctrl) were purchased from GeneCopoeia (Guangzhou, China) and cloned into the pEZX-MR03 and pEZX-AM03 lentiviral expression vectors, respectively. MHCC97-H and Hep3B cells were infected with recombinant lentiviruses at an MOI of 10 .

Plasmids and siRNA transfection. PTP4A1 plasmids was obtained from GeneCopoeia and cloned into the pcDNA3.1 expression vectors (Invitrogen, Carlsbad, CA, USA). PTP4A1 specific siRNA and negative control siRNA were purchased from Guangzhou RiboBio Co., Ltd. (Guangzhou, China). The PTP4A1 expression vector or PTP4A1 siRNA were transfected into the HCC cells using Lipofectamine 3000 (Invitrogen) according to the manufacturer's instructions.

Reverse transcription-quantitative polymerase chain reaction $(R T-q P C R)$. Total RNA from tissues and cultured cells was isolated using TRIzol reagent (Invitrogen). The Bulge-Loop miR-1271 qRT-PCR Primer Set (Guangzhou RiboBio) was used to determine miR-1271 expression. PTP4A1 mRNA levels normalized to GAPDH were measured by RT-qPCR using the SuperScrip III Reverse Transcriptase kit (Invitrogen) and the iTaq Universal SYBR-Green Supermix kit (Bio-Rad Laboratories, Hercules, CA, USA). The primer sequences were as follows: PTP4A1 forward, 5'-ACCAATGCGACCTTAAC AAA-3' and reverse, 5'-ATCTGGTTGGATGGTGGTG-3'; and GAPDH forward, 5'-CCAGGGCTGCTTTTAACTCT-3' and reverse, 5'-GGACTCCACGACGTACTCA-3'). The thermocycling conditions are: Holding stage $50^{\circ} \mathrm{C}$ for $2 \mathrm{~min}$, $95^{\circ} \mathrm{C}$ for $10 \mathrm{~min}$; PCR stage (40 times) $95^{\circ} \mathrm{C}$ for $15 \mathrm{sec}, 60^{\circ} \mathrm{C}$ for $1 \mathrm{~min}$.

Western blot analysis. Western blot analysis was used to detect the expression of PTP4A1, E-cadherin, N-cadherin, vimentin, c-Src, the phosphorylation of c-Src (Y416), Snail, matrix metalloproteinase (MMP)-9 and GAPDH in cultured cell lysates. The cells were lysed by RIPA buffer (Heart Biological Technology Co., Ltd., Xian, China) and quantified using the BCA protein assay kit II (\#5000002; Bio-Rad Laboratories). The protein sample $(40 \mu \mathrm{g})$ was separated on a $10 \%$ SDS-PAGE gel and transferred onto nitrocellulose membranes (Invitrogen) using the Bio-Rad Tank Blotting system (Bio-Rad Laboratories). The membranes were respectively incubated with primary antibodies at a 1:1,000 dilution overnight at $4^{\circ} \mathrm{C}$. The purchased primary antibodies were listed as follows: PTP4A1 (11508-1-AP) and N-cadherin (22018-1-AP) from Proteintech Group, Inc. (Rosemont, IL, USA); N-cadherin (\#3195), vimentin (\#3932), c-Src (\#2109) and phosphorylated c-Src (p-c-Src;Y416, \#6943) from Cell Signaling Technology (Danvers, MA, USA); Snail (ab53519) antibody from Abcam (Cambridge, MA, USA); MMP-9 (sc-21733) and GAPDH (sc-47724) antibodies were from Santa Cruz Biotechnology (Dallas, TX, USA). Horseradish peroxidase-conjugated secondary antibodies at a 1:2,000 dilution were used to incubate the membranes for $1 \mathrm{~h}$ at room temperature after washing them by TBST 3 times for $10 \mathrm{~min}$. The targeting proteins on the membrane were visualized with ECL reagents (Millipore, Plano, TX, USA).

Immunohistochemistry. Briefly, paraformaldehyde-fixed paraffin tumor tissue sections were performed for immunohistochemical staining. PTP4A1 primary antibodies were diluted at 1:100 with phosphate-buffered saline (PBS) to label the antigens at $4^{\circ} \mathrm{C}$ overnight. Biotinylated goat anti-rabbit secondary antibodies (ZSGB-Bio, Beijing, China) were used to label the combined primary antibodies. Complexes were detected by HRP-streptavidin conjugates (ZSGB-Bio) and visualized by DAB (ZSGB-Bio). The final scores were calculated by the product of staining intensity and positive staining cell percentage as previously described (19).

In vitro migration and invasion assays. For in vitro experiments, wound healing assay, Transwell migration assay and Transwell invasion assay were used to determine cell migration and invasion.

For wound healing assay, a wound line across the middle of 6-well plates with confluent cells was created using a $200 \mu \mathrm{l}$ sterile tip. The cells were cultured in reduced serum DMEM medium in a humidified $5 \% \mathrm{CO}_{2}$ incubator at $37^{\circ} \mathrm{C}$ for $48 \mathrm{~h}$, and then images were taken with a phase-contrast microscope.

Transwell inserts (Nalge Nunc International, Penfield, New York, NY, USA) were coated with Matrigel (BD Biosciences, Franklin Lakes, NJ, USA) at $1 \mathrm{mg} / \mathrm{ml}$ on the upper layer for invasion assay. Uncoated inserts were used for migration assay. Briefly, $5 \times 10^{4}$ cells were seeded into the upper chamber with reduced serum DMEM medium. Subsequenlty, $750 \mu 1$ DMEM medium containing $10 \%$ FBS was added to the lower chamber. The cells were incubated in a humidified $5 \% \mathrm{CO}_{2}$ incubator at 

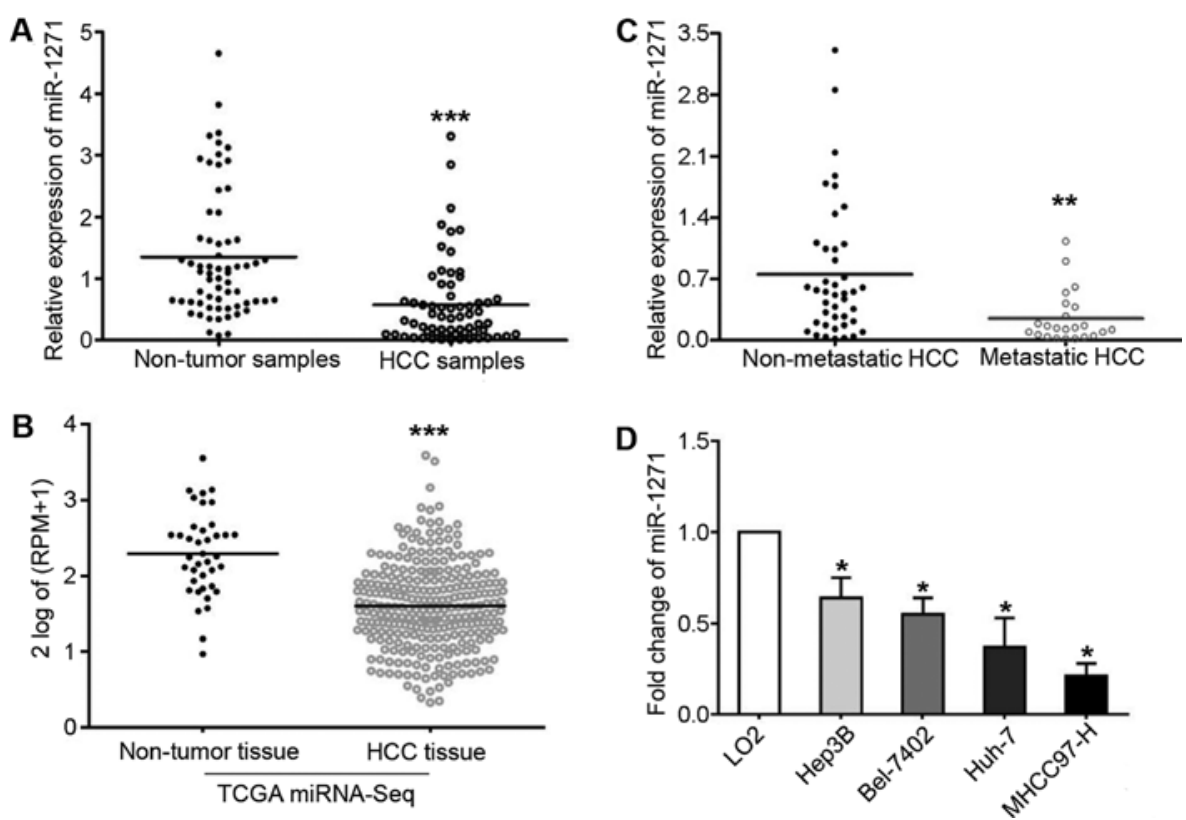

Figure 1. The expression of miR-1271 is downregulated in HCC. (A) Differential expression of miR-1271 detected in 65 paired HCC tissues and matched nontumor tissues. (B) Downregulation of miR-1271 in $271 \mathrm{HCC}$ tissues and 39 normal liver tissues from the TCGA data set. ${ }^{* * *} \mathrm{P}<0.001$, compared with non-tumor tissues. RPM, reads per million mapped reads. (C) The expression of miR-1271 was compared between non-metastatic and metastatic HCC tissues. ${ }^{* *} \mathrm{P}<0.01$, compared with non-metastatic HCC samples. (D) miR-1271 expression levels were detected in normal hepatic cells (LO2) and 4 HCC cell lines (MHCC97-H, Bel-7402, Huh-7 and Hep3B). "P<0.05, compared with LO2 cells. The values are presented as the means \pm SD from triplicate experiments.

$37^{\circ} \mathrm{C}$ for $24 \mathrm{~h}$. The chambers were fixed in $4 \%$ paraformaldehyde for $5 \mathrm{~min}$ and then stained with $0.3 \%$ crystal violet dye for $10 \mathrm{~min}$. The cells on the upper layer were removed with a cotton swab. Migrating or invading cells were counted under a light microscope.

In vivo metastasis analysis. For the in vivo metastasis model, $16 \mathrm{BALB} / \mathrm{cA}$, 4-6-week-old, 16-18 g, female nude mice were housed in sterilized cages with appropriate environment $\left(25^{\circ} \mathrm{C}, 45 \%\right.$ humidity) and fed a regular chow diet with water ad libitum. All animal protocols were approved by the Biomedical Ethics Committee of Xi'an Jiaotong University Health Science Center. The mice were randomly divided into 4 groups as follows: i) those injected with MHCC97-H cells transfected with miR-1271 overexpression vector; ii) those injected with MHCC97H cells transfected with miRctrl vector; iii) those injected with Hep3B cells transfected with anti-miR-1271 vector; and iv) those injected with Hep3B cells transfected with anti-miR-ctrl vector. The cells were suspended in cold $1 \mathrm{X}$ PBS buffer at a concentration of $1 \times 10^{5} / \mathrm{ml}$. Each mouse was injected with a $100 \mu \mathrm{l}$ cell suspension $\left(\sim 1 \times 10^{4}\right.$ cells $)$ into the tail vein very slowly to establish the lung metastasis model. After 28 days, the weight of all mice increased up to $20-23 \mathrm{~g}$. The mice were sacrificed by $\mathrm{CO}_{2}$ euthanasia (the flow rate of $\mathrm{CO}_{2}$ was $20 \%$ displace$\mathrm{ment} / \mathrm{min}$ ). The lungs were then removed and formalin-fixed, paraffin-embedded sections were created for H\&E staining (Heart Biological Technology Co., Ltd.).

Dual-Luciferase reporter assay. Two online MicroRNA targets prediction tools, TargetScan (http://www.targetscan. org/) and MiRanda (http://www.microrna.org/), were used to located the binding sites between miR-1271 and PTP4A1 3'-UTR region. The 3'-UTR sequence of PTP4A1 predicted to interact with miR-1271 and the designed mutant 3'-UTR sequence were synthesized and inserted into the pEZX-MT06 vector (GeneCopoeia). These two recombinant constructs were identified as wild-type 3'-UTR vector and mutant type 3'-UTR vector, respectively and transfected into the MHCC-97H cells. miR-1271 mimics (Guangzhou Ribobio) were transfected into these cells at the same time. After $48 \mathrm{~h}$, the cells were harvested and luciferase activity was measured using the Luc-Pair ${ }^{\mathrm{TM}}$ Duo-Luciferase Assay kit 2.0 (GeneCopoeia). Firefly luciferase activity was normalized to Renilla luciferase activity.

Statistical analyses. Continuous variables are presented as the means \pm standard deviation (SD). Statistical analysis was performed using the SPSS version 21.0 software (SPSS Inc., Chicago, IL, USA) or GraphPad PRISM 5 software (GraphPad Software, La Jolla, CA, USA). Correlations between miR-1271 and clinicopathological data were analyzed by the Pearson's Chi-square test. The differences between groups were analyzed using a Student's t-test. One-way ANOVA was used to analyze the data from more than two groups. Bonferroni method was used as a post hoc test. Survival analysis was performed using a Kaplan-Meier curve and log-rank test. A value of $\mathrm{P}<0.05$ was considered to indicate a statistically significant difference.

\section{Results}

Downregulation of miR-1271 is associated with metastasis in human HCC. We analyzed miR-1271 expression by RT-qPCR and found that it was frequently downregulated in HCC tissues $(\mathrm{P}=0.007$; Fig. 1A). Consistent with our findings, miR-1271 was also discovered to be markedly downregulated in 271 HCC tissues obtained from the TCGA miRNA-Seq data set $(\mathrm{P}<0.001$; Fig. 1B). These findings encouraged us to further 
A
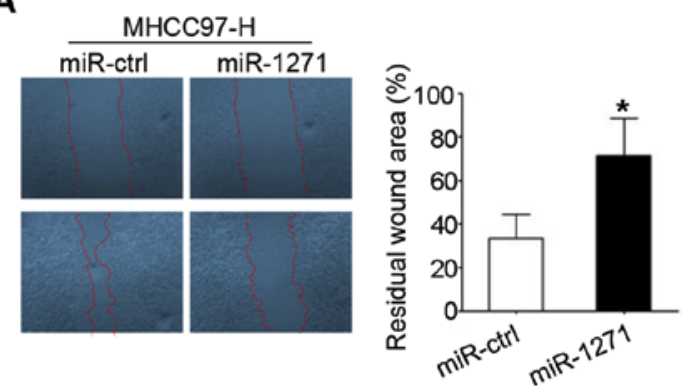

C
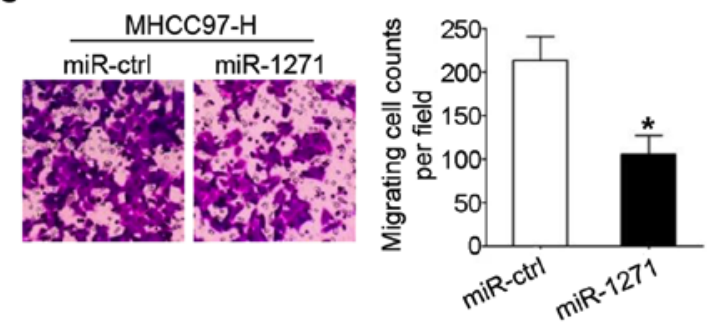

E

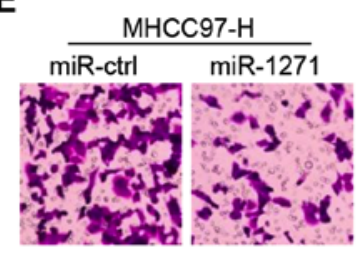

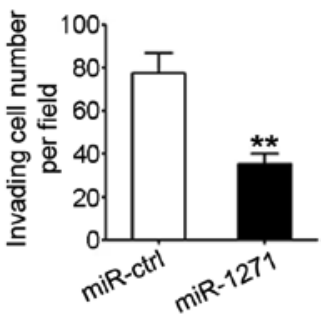

B
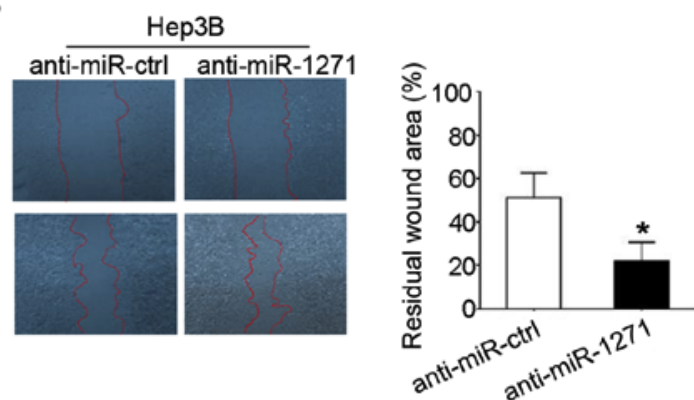

D
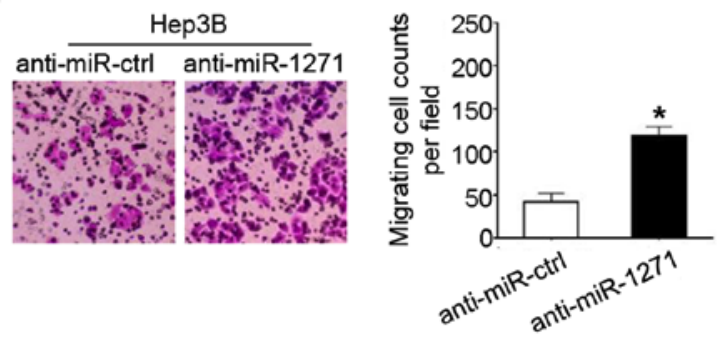

F

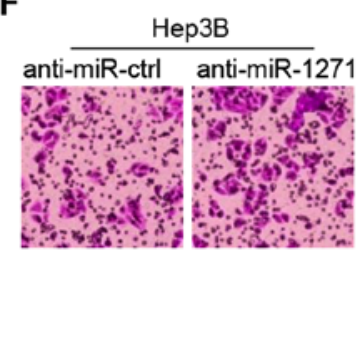

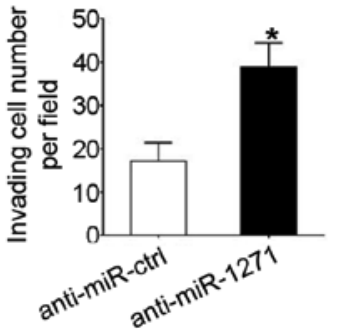

Figure 2. miR-1271 inhibits HCC cell migration and invasion in vitro. The upregulation of miR-1271 was demonstrated to inhibit MHCC97-H cell migration by (A) wound healing assay, (C) Transwell migration assay and invasion by (E) Transwell invasion assay. * $\mathrm{P}<0.05$, compared with the miR-ctrl group. Downregulation of miR-1271 was demonstrated to promote Hep3B cell migration by (B) wound healing assay, (D) Transwell migration assay and invasion by (F) Transwell invasion assay. ${ }^{*} \mathrm{P}<0.05,{ }^{* *} \mathrm{P}<0.01$, compared with the anti-miR-ctrl group. All values are presented as the means \pm SD from triplicate experiments.

demonstrate a lower expression of miR-1271 in metastatic HCC tissues compared with non-metastatic tissues $(\mathrm{P}=0.004$; Fig. 1C). Moreover, we determined the expression levels of miR-1271 in 4 HCC cell lines and LO2 cells. As shown in Fig. 1D, a significant change was confirmed by one-way ANOVA analysis in these 5 cell lines $(\mathrm{P}<0.05)$. Furthermore, all 4 HCC cell lines expressed decreased levels of miR-1271 compared with the $\mathrm{LO} 2$ cells $(\mathrm{P}<0.05$, respectively).

Inhibitory effects of miR-1271 on metastasis and EMT in $H C C$. After examining the expression of miR-1271 in different HCC cell lines, we overexpressed miR-1271 in MHCC97-H cells by transfection with miR-1271 lentivirus, and knocked down its expression levels in Hep3B cells by transfection with anti-miR-1271 lentivirus (data not shown). Wound healing assays were used to demonstrate that miR-1271 overexpression inhibited the migration of the MHCC97-H cells $(\mathrm{P}=0.021$; Fig. 2A), whereas miR-1271 knockdown promoted the migration of the Hep3B cells $(\mathrm{P}=0.031$; Fig. $2 \mathrm{~B})$. The inhibitory effect of miR-1271 on HCC cell migration was also be confirmed by a Transwell chamber model $(\mathrm{P}=0.030$ and $\mathrm{P}=0.034$; Fig. 2C and D). Similarly, in the Transwell chamber invasion assays, the upregulation of miR-1271 decreased the invasion of the MHCC97-H cells $(\mathrm{P}=0.009$; Fig. 2E) and the downregulation of miR-1271 increased the invasion of the Hep3B cells $(\mathrm{P}=0.031$; Fig. $2 \mathrm{~F})$.

To further investigate the effects of miR-1271 on tumor metastasis in vivo, we established a lung metastasis model by tail vein injection of HCC cells, and the maximum number of lung metastatic clusters number of a single lung we found was measured and found to be 19. As shown in Fig. 3A, the total number of lung metastatic clusters in the miR-1271 group was much lower than that in the miR-ctrl group $(\mathrm{P}=0.007)$. By contrast, a promoting effect on in vivo tumor metastasis induced by miR-1271 knockdown was observed in nude mice injected with recombinant Hep3B cells ( $\mathrm{P}=0.029$; Fig. 3B). Taken together, these results demonstrated that miR-1271 significantly inhibited the metastasis of HCC cells in vitro and in vivo.

As already discussed above, EMT serves as a microfoundation for cancer metastasis. Thus, we evaluated whether miR-1271 regulates the EMT phenotype of HCC cells. As shown in Fig. 3C, the results from western blot analysis revealed that the re-induction of miR-1271 in the MHCC97-H cells increased the expression of epithelial markers (E-cadherin, $\mathrm{P}<0.05)$ but decreased the expression levels of 
A
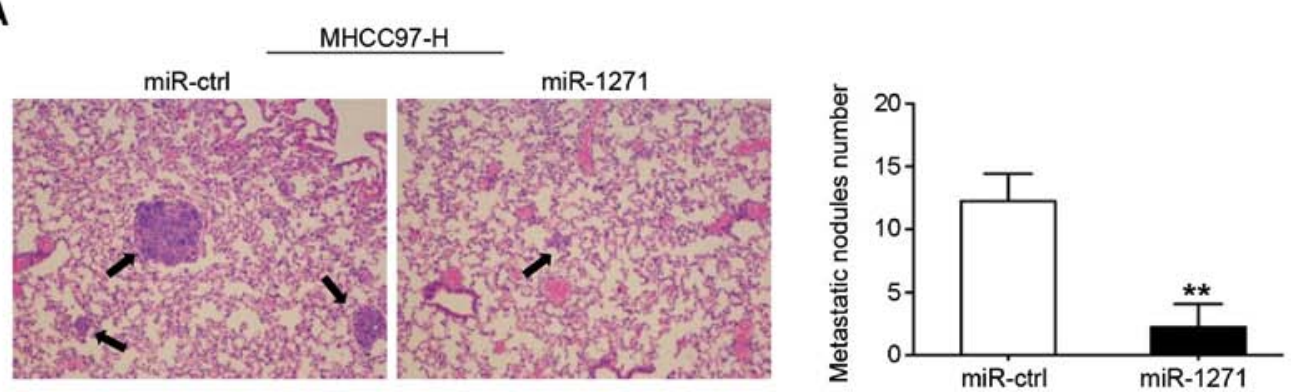

B
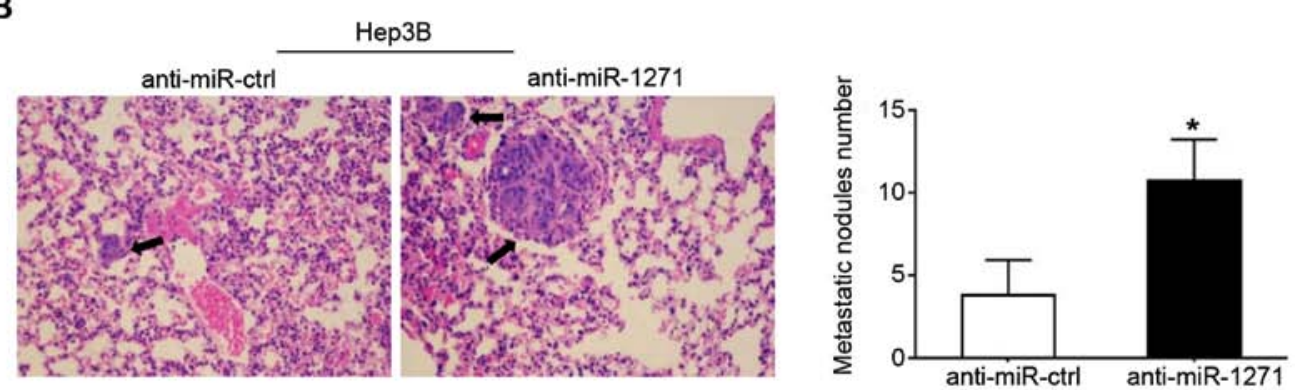
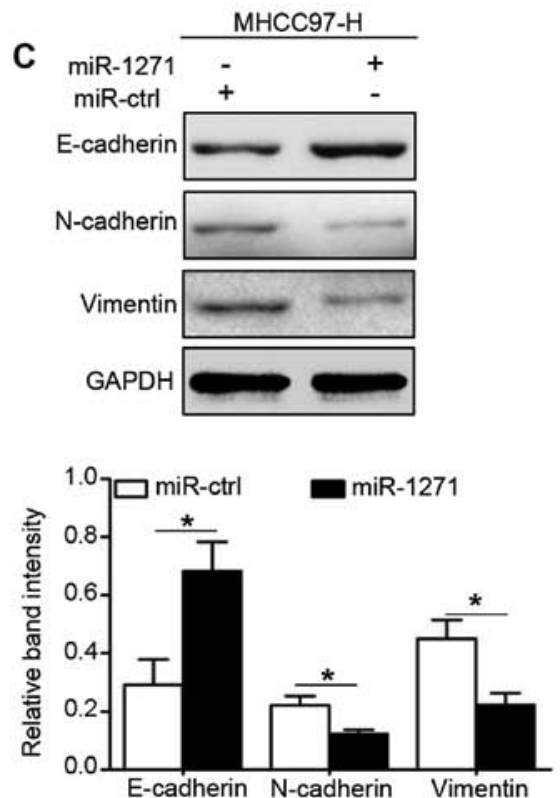
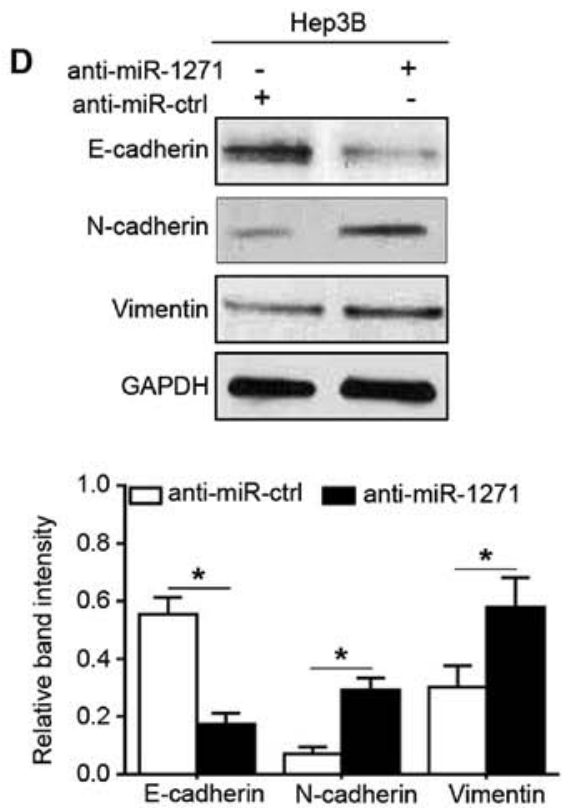

Figure 3. miR-1271 suppresses HCC lung metastasis and EMT. (A) miR-1271 overexpression decreased the number of lung metastatic nodules; $n=4 ;{ }^{* *} \mathrm{P}<0.01$, compared with the miR-ctrl group. (B) miR-1271 inhibition increased the number of lung metastatic nodules; $\mathrm{n}=4$; ${ }^{\mathrm{P}}<0.05$, compared with the anti-miR-ctrl group. Metastatic nodule was labeled by black arrow. (C) Upregulation of miR-1271 induced the expression of E-cadherin, but inhibited the expression of $\mathrm{N}$-cadherin and vimentin. "P $<0.05$, compared with the miR-ctrl group. (D) Downregulation of miR-1271 decreased the expression of E-cadherin, but increased the expression of $\mathrm{N}$-cadherin and vimentin. ${ }^{*} \mathrm{P}<0.05$, compared with the miR-ctrl group. The values in $(\mathrm{C}$ and $\mathrm{D})$ are presented as the means $\pm \mathrm{SD}$ from triplicate experiments.

mesenchymal markers $(\mathrm{N}$-cadherin and vimentin; $\mathrm{P}<0.05$, respectively). On the contrary, miR-1271 knockdown induced EMT by decreasing E-cadherin expression and increasing the expression of two mesenchymal markers expression (Fig. 3D; $\mathrm{P}<0.05$, respectively).

PTP4A1 is a direct downstream target of miR-1271. To investigate the targets through which miR-1271 suppresses HCC metastasis, we used two online databases (TargetScan, http:// www.targetscan.org/ and MiRanda http://www.microrna.org/) to predict that PTP4A1 was a high potential target of miR-1271 in HCC (Context++ score percentile, 99\%; miRSVR score: -0.7645; Fig. 4A). To confirm this prediction, we first used a Dual-Luciferase reporter system to demonstrate that miR-1271, as we had expected, suppressed the luciferase activity of PTP4A1 with a wild-type 3'-UTR, but did not suppress the activity of PTP4A1 containing a mutant type 3'-UTR $(\mathrm{P}=0.035$; Fig. 4B). In addition, the results from RT-qPCR and western blot analysis revealed that miR-1271 negatively modulated the mRNA and protein levels of PTP4A1 in the HCC cells $(\mathrm{P}<0.05$, respectively; Fig. $4 \mathrm{C}$ and $\mathrm{D})$. Importantly, our study revealed a negative correlation between miR-1271 levels 
A

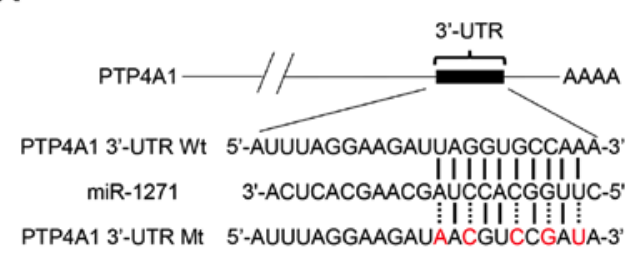

B

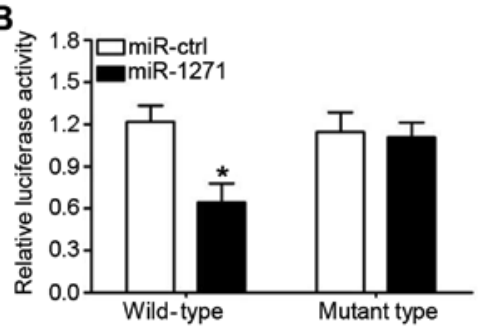

C

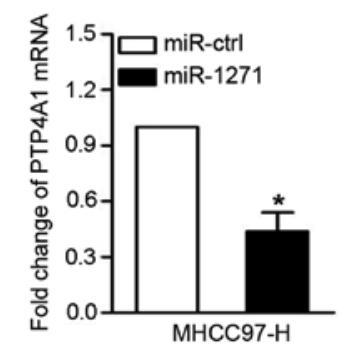

D

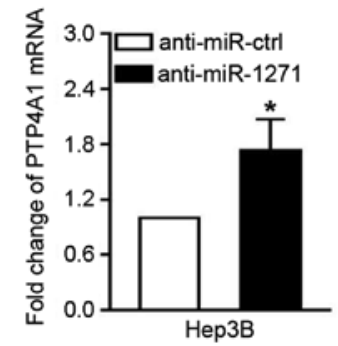

E

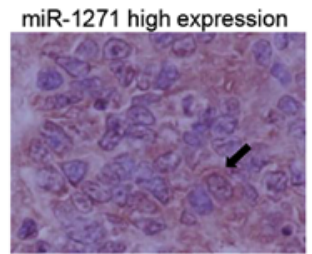

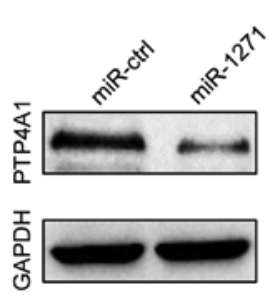
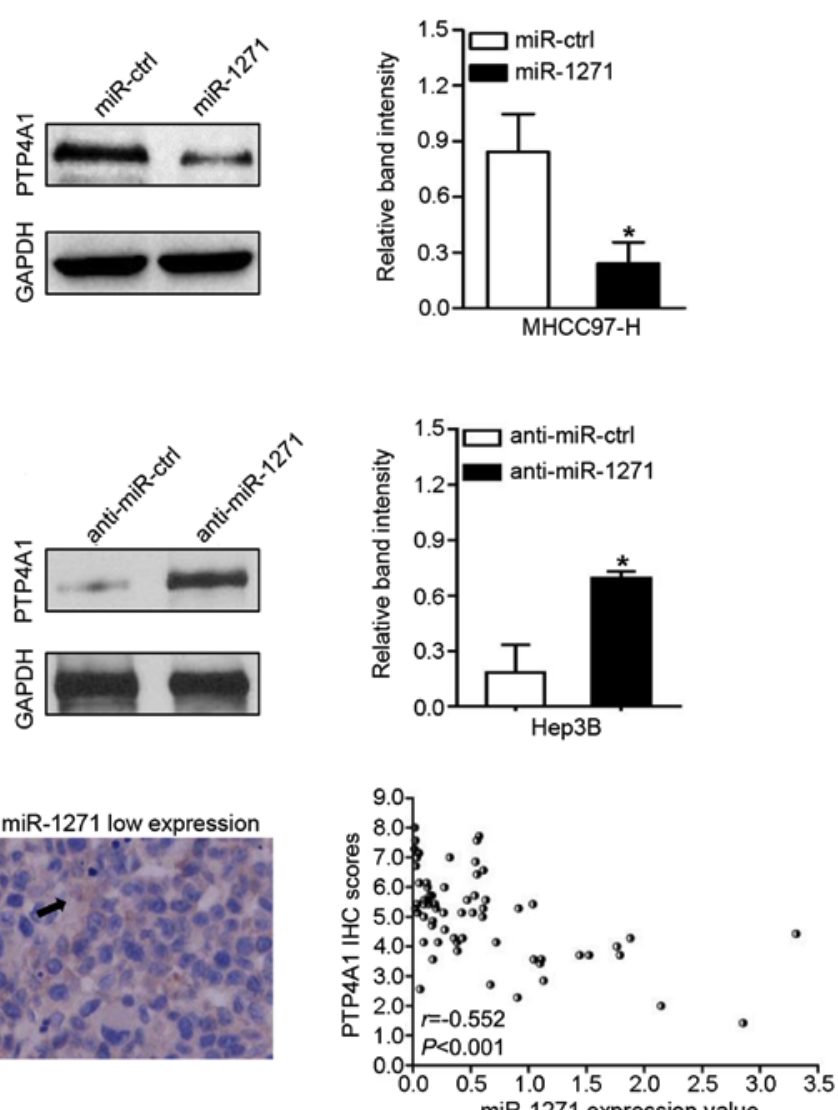

Figure 4. PTP4A1 is a direct target of miR-1271 in HCC. (A) The putative binding set and corresponding mutant sequence in the 3 '-UTR of PTP4A1 for miR-1271. (B) miR-1271 only decreased the luciferase activity that carried wild-type 3'-UTR of PTP4A1. *P<0.05, compared with the mutant-type group. (C) Upregulation of miR-1271 inhibited PTP4A1 mRNA and protein expression levels. * $<<0.05$, compared with the miR-ctrl group. (D) Downregulation of miR-1271 induced PTP4A1 mRNA transcription and protein expression. ${ }^{*} \mathrm{P}<0.05$, compared with the anti-miR-ctrl group. The values in (B), (C) and (D) are presented as the means \pm SD from triplicate experiments. (E) Negative correlations between miR-1271 and PTP4A1 expression in HCC tissues, $\mathrm{r}=-0.552$, $\mathrm{P}<0.001$. Positive staining cell is labeled by black arrows.

and PTP4A1 protein expression in 65 HCC tissues $(r=-0.552$, $\mathrm{P}<0.001$; Fig. 4E). On the whole, these results strongly indicate that PTP4A1 is a target of miR-1271 in HCC.

Alterations in PTP4Al expression abrogate the effects of miR-1271 on HCC cells. To further confirm these results, we repeated the above-mentioned in vitro experiments using another method. We transfected PTP4A1 vectors into the cells to increase PTP4A1 expression in the MHCC97-H cells that stably overexpressed miR-1271 (by transfection with miR-1271 expression vector; $\mathrm{P}<0.001$ and $\mathrm{P}=0.031$, respectively; Fig. 5A), and used PTP4A1 siRNA (si-PTP4A1) to knockdown PTP4A1 expression in the Hep3B cells with a stably decreased expression of miR-1271 (by transfection with miR-1271 inhibitor; $\mathrm{P}<0.001$ and $\mathrm{P}=0.016$, respectively; Fig. 5B). PTP4A1 overexpression increased the migration ( $\mathrm{P}=0.007$; Fig. 6A), invasion $(\mathrm{P}=0.024$; Fig. $6 \mathrm{~B})$ and mesenchymal transition
$(\mathrm{P}<0.05$, respectively; Fig. 6C) in miR-1271-overexpressing MHCC97-H cells. Similarly, PTP4A1 knockdown decreased the migration $(\mathrm{P}=0.040$; Fig. 6D) and invasion $(\mathrm{P}=0.033$, Fig. 6E) and inhibited EMT $(\mathrm{P}<0.05$, respectively; Fig. $6 \mathrm{~F})$ in the Hep3B cells transfected with anti-miR-1271.

miR-1271 prevents HCC metastasis by inducing c-Src phosphorylation. To explore the underlying mechanisms of PTP4A1 in the regulation of HCC metastasis, we used western blot analysis to detect the expression of total c-Src expression, the phosphorylation of c-Src and two metastasis-associated c-Src downstream targets (Snail and MMP-9). As we had expected, the expression levels of c-Src ${ }^{\mathrm{Y} 416}$, Snail and MMP-9 were downregulated in the MHCC97-H cells that stably overexpressed miR-1271 ( $\mathrm{P}<0.05$ and $\mathrm{P}<0.01$, respectively; Fig. 7A, left lanes), and were upregulated in the Hep3B cells in which miR-1271 was inhibited $(\mathrm{P}<0.05$ and $\mathrm{P}<0.01$, respectively; 

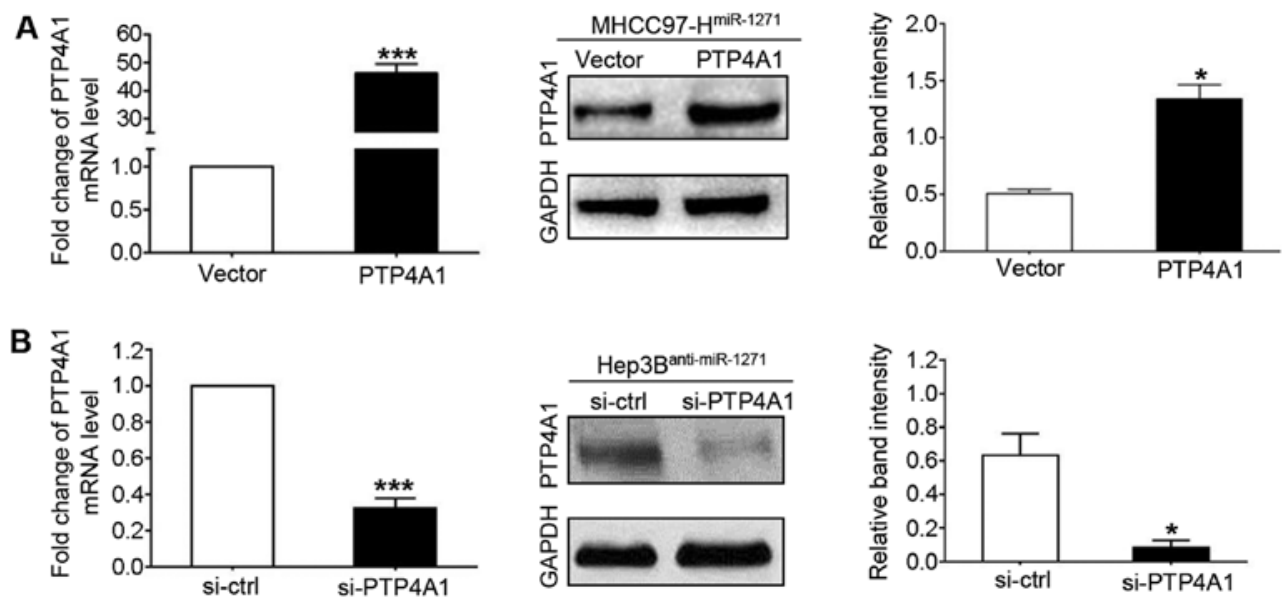

Figure 5. PTP4A1 expression levels are altered in HCC cells. (A) The mRNA and protein expression levels of PTP4A1 were increased by transfection with PTP4A1 expression vector. ${ }^{* * *} \mathrm{P}<0.001,{ }^{*} \mathrm{P}<0.05$, compared with the negative control vector group. (B) siRNA transfection decreased PTP4A1 expression. ${ }^{* * *} \mathrm{P}<0.001,{ }^{*} \mathrm{P}<0.05$, compared with the si-ctrl group. All values are presented as the means $\pm \mathrm{SD}$ from triplicate experiments.

A

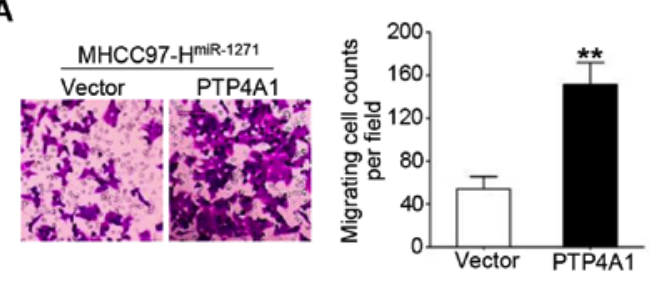

C

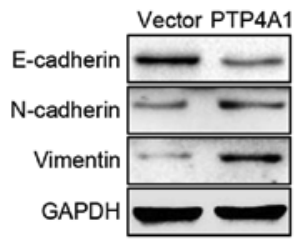

D

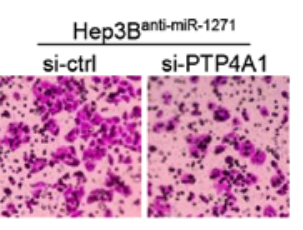

B
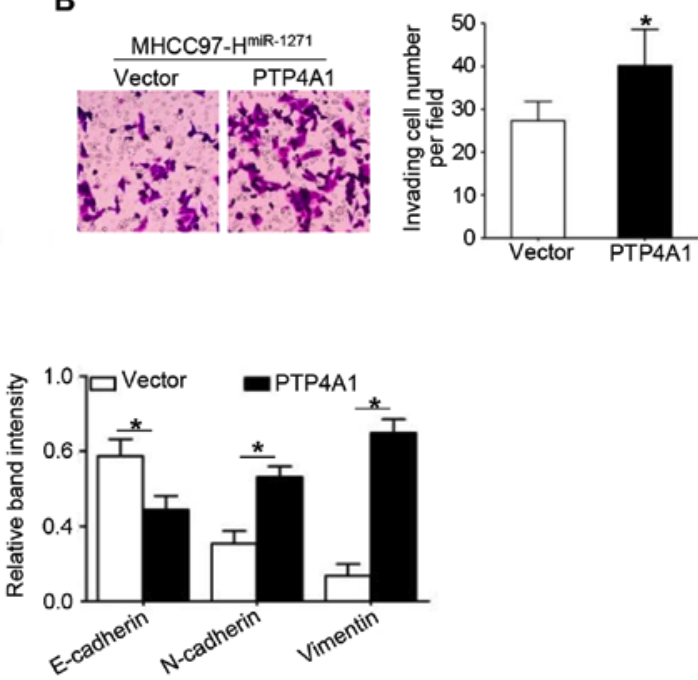
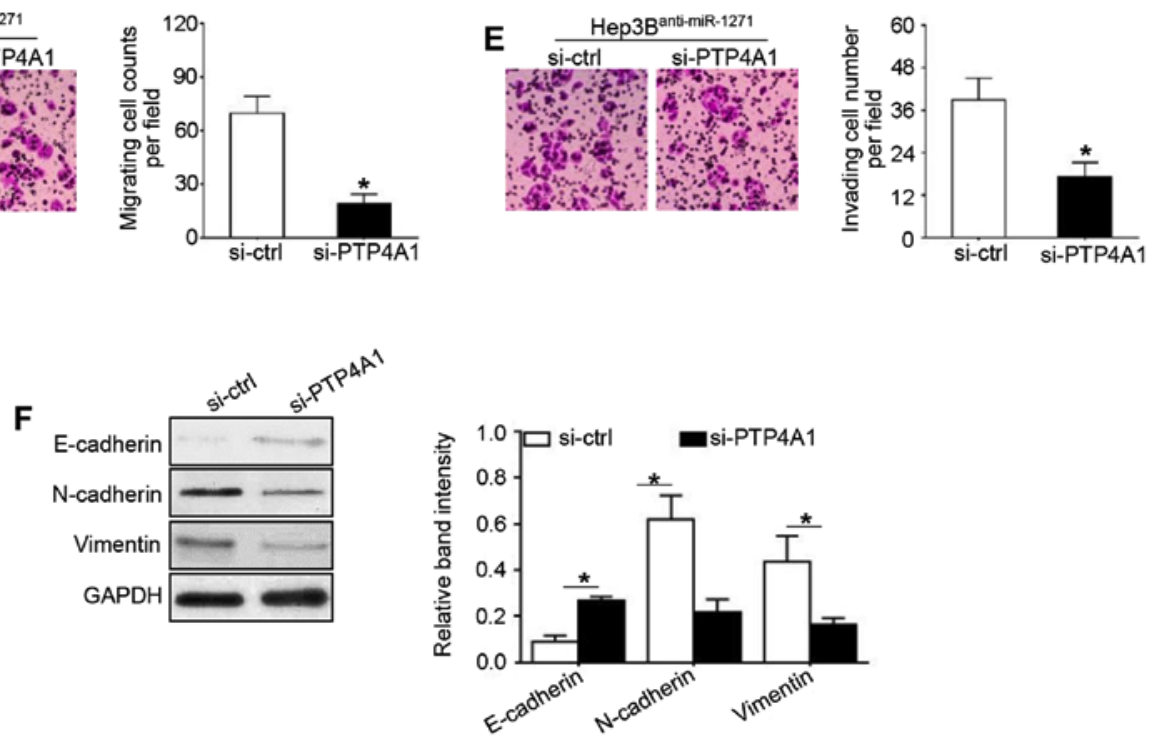

Figure 6. PTP4A1 alternations abrogate the effects of miR-1271 in HCC cells. Restoration of PTP4A1 increased (A) cell migration, (B) invasion and (C) EMT in miR-1271-overexpressing MHCC97-H cells. ${ }^{*} \mathrm{P}<0.05,{ }^{* *} \mathrm{P}<0.01$, compared with negative control vector group. PTP4A1 knockdown attenuated (D) migration, (E) invasion and (F) EMT in Hep3B cells in which miR-1271 was suppressed. " $\mathrm{P}<0.05$, compared with the si-ctrl group. All values are presented as the means \pm SD from triplicate experiments. 
A
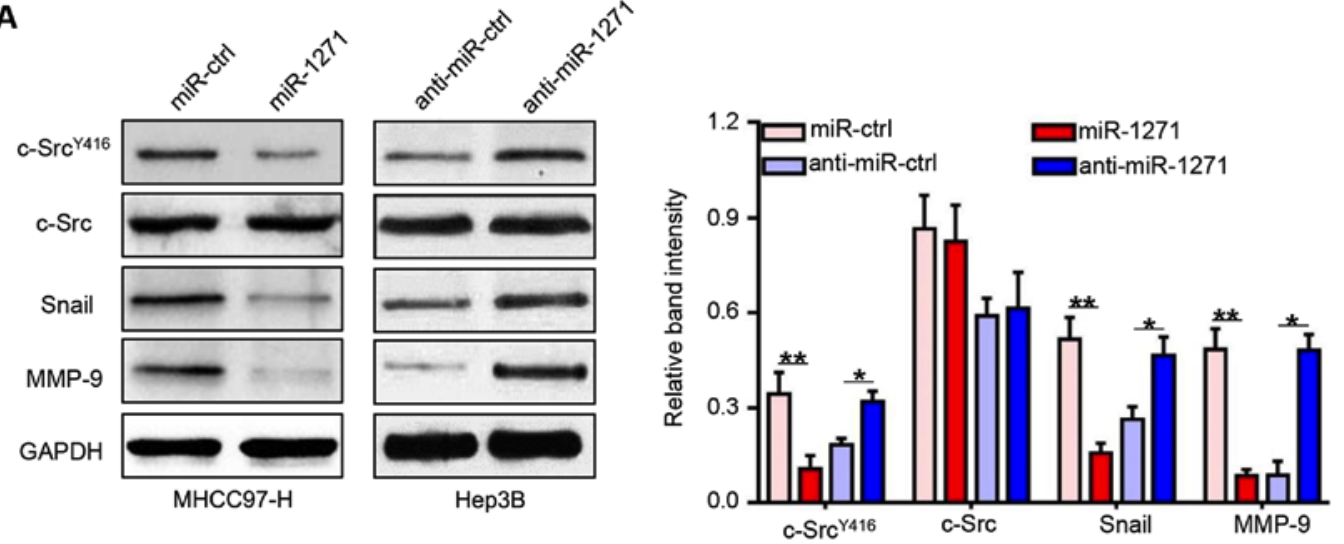

B
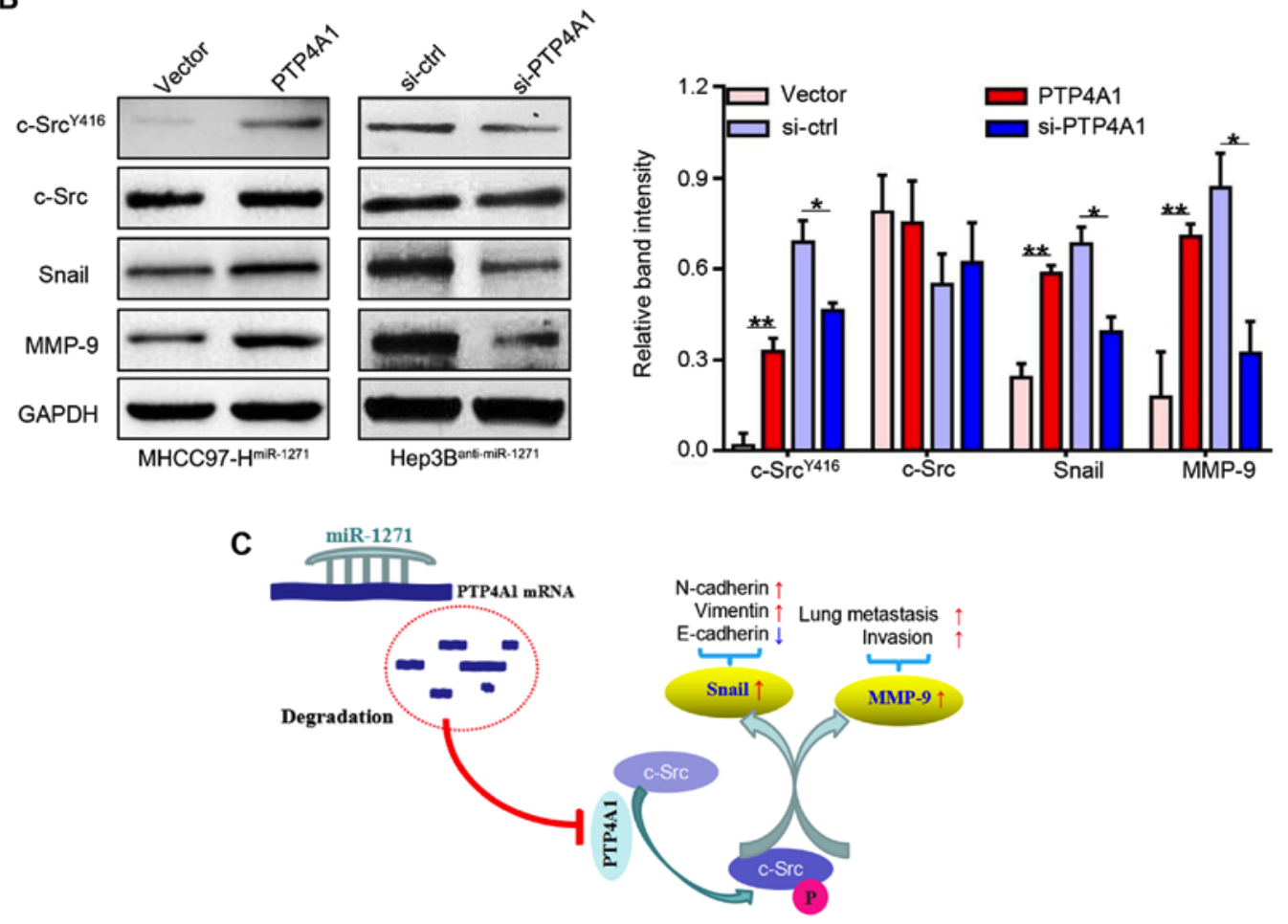

Figure 7. miR-1271 carries out its functions by inhibiting the PTP4A1/c-Src signaling pathway. (A) The expression levels of c-Src ${ }^{\mathrm{Y} 416}$, Snail and MMP-9 were decreased by the upregulation of miR-1271 expression in MHCC97-H cells, but increased by the downregulation of miR-1271 expression in Hep3B cells. ${ }^{*} \mathrm{P}<0.05,{ }^{* *} \mathrm{P}<0.01$, compared with the miR-ctrl group and anti-miR-ctrl group. (B) Restoration of PTP4A1 increased the expression levels of c-Src ${ }^{\mathrm{Y} 416}$, Snail and MMP-9 which were inhibited by miR-1271 overexpression; by contrast, PTP4A1 knockdown suppressed these expression levels. ${ }^{*} \mathrm{P}<0.05,{ }^{* *} \mathrm{P}<0.01$, compared with the negative control vector group and si-ctrl group. All values are presented as the means \pm SD from triplicate experiments. (C) Diagrammatic sketch of the signaling pathway that miR-1271 arrests tumor metastasis and EMT on HCC.

Fig. 7A, right lanes). By contrast, the expression levels of these genes were increased following transfection with PTP4A1 expression vector $(\mathrm{P}<0.05$ and $\mathrm{P}<0.01$, respectively; Fig. 7B, left lanes). Moreover, transfection with si-PTP4A1 decreased the expression levels of these genes, which was similar to the effects induced by miR-1271 overexpression $(\mathrm{P}<0.05$ and $\mathrm{P}<0.01$, respectively; Fig. 7B, right lanes). These results thus indicate that the multiple anticancer functions of miR-1271 are attributed to the inhibition of the PTP4A1/c-Src signaling pathway (Fig. 7C).

Clinical significance of miR-1271 and PTP4A1 in human HCC. We divided the 65 HCC patients into 2 groups according to the mean value of miR-1271 expression or PTP4A1 IHC scores. As shown in Table I, a low expression of miR-1271 was associated with tumor metastasis $\left(\chi^{2}=6.040, \mathrm{P}=0.014\right)$ and an advanced TNM stage (III+IV stage, $\chi^{2}=5.298, \mathrm{P}=0.021$ ). Moreover, a high expression of PTP4A1 was associated with a large tumor size ( $\left.>5 \mathrm{~cm}, \chi^{2}=6.023, \mathrm{P}=0.014\right)$, tumor metastasis $\left(\chi^{2}=4.190\right.$, $\mathrm{P}=0.041)$ and an advanced TNM stage $\left(\chi^{2}=5.747, \mathrm{P}=0.017\right)$. Kaplan-Meier survival curves revealed that patients in the low miR-1271 expression group had a poorer 3-year overall survival rate $(\mathrm{HR}=2.597, \mathrm{P}=0.001 ; \mathrm{Fig} .8 \mathrm{~A})$ and tumor-free survival rate $(\mathrm{HR}=2.864, \mathrm{P}<0.001$; Fig. 8B) compared with patients in the high miR-1271 group. Furthermore, the 3-year overall survival rate $(\mathrm{HR}=2.172, \mathrm{P}=0.008$; Fig. $8 \mathrm{C})$ and tumor-free survival rate $(\mathrm{HR}=2.780, \mathrm{P}<0.001$; Fig. 8D) were lower in the high PTP4A1 expression group than the low PTP4A1 expression group. On the whole, these data suggest that miR-1271 and PTP4A1 are prognostic indicators for patients with HCC. 
Table I. Correlation between the clinicopathological characteristics and miR-1271 and PTP4A1 expression in patients with HCC $(n=65)$

\begin{tabular}{|c|c|c|c|c|c|c|c|c|}
\hline \multirow[b]{2}{*}{ Clinical characteristics } & \multicolumn{2}{|c|}{ miR-1271 expression } & \multirow[b]{2}{*}{$\chi^{2}$} & \multirow[b]{2}{*}{$\mathrm{P}$-value } & \multicolumn{2}{|c|}{ PTP4A1 expression } & \multirow[b]{2}{*}{$\chi^{2}$} & \multirow[b]{2}{*}{ P-value } \\
\hline & Low $(n=44)$ & $\operatorname{High}(\mathrm{n}=21)$ & & & Low $(n=28)$ & High $(n=37)$ & & \\
\hline \multicolumn{9}{|l|}{ Sex } \\
\hline Male & 30 & 9 & 3.799 & 0.051 & 15 & 24 & 0.847 & 0.357 \\
\hline Female & 14 & 12 & & & 13 & 13 & & \\
\hline \multicolumn{9}{|l|}{ Age (years) } \\
\hline$<50$ & 17 & 11 & 1.095 & 0.295 & 10 & 18 & 1.087 & 0.297 \\
\hline$\geq 50$ & 27 & 10 & & & 18 & 19 & & \\
\hline \multicolumn{9}{|l|}{ HBsAg } \\
\hline Negative & 11 & 4 & 0.047 & 0.828 & 7 & 8 & 0.102 & 0.749 \\
\hline Positive & 33 & 17 & & & 21 & 29 & & \\
\hline \multicolumn{9}{|l|}{ Liver cirrhosis } \\
\hline Absent & 15 & 12 & 3.111 & 0.078 & 15 & 12 & 2.933 & 0.087 \\
\hline Present & 29 & 9 & & & 13 & 25 & & \\
\hline \multicolumn{9}{|l|}{ Tumor size $(\mathrm{cm})$} \\
\hline$\leq 5$ & 14 & 12 & 3.799 & 0.051 & 16 & 10 & 6.023 & $0.014^{\mathrm{a}}$ \\
\hline$>5$ & 30 & 9 & & & 12 & 27 & & \\
\hline \multicolumn{9}{|c|}{ Edmondson-Steiner grading } \\
\hline $\mathrm{I}+\mathrm{II}$ & 19 & 14 & 3.137 & 0.077 & 18 & 15 & 3.596 & 0.058 \\
\hline III+IV & 25 & 7 & & & 10 & 22 & & \\
\hline \multicolumn{9}{|l|}{ Metastasis } \\
\hline Absent & 24 & 18 & 6.040 & $0.014^{\mathrm{a}}$ & 22 & 20 & 4.190 & $0.041^{\mathrm{a}}$ \\
\hline Present & 20 & 3 & & & 6 & 17 & & \\
\hline \multicolumn{9}{|l|}{ TNM stage } \\
\hline $\mathrm{I}+\mathrm{II}$ & 18 & 15 & 5.298 & $0.021^{\mathrm{a}}$ & 19 & 14 & 5.747 & $0.017^{\mathrm{a}}$ \\
\hline III+IV & 26 & 6 & & & 9 & 23 & & \\
\hline
\end{tabular}

HBsAg, Hepatitis B surface antigen; TNM, tumor-node metastasis. ${ }^{\mathrm{P}}<0.05$, indicates statistical significance.
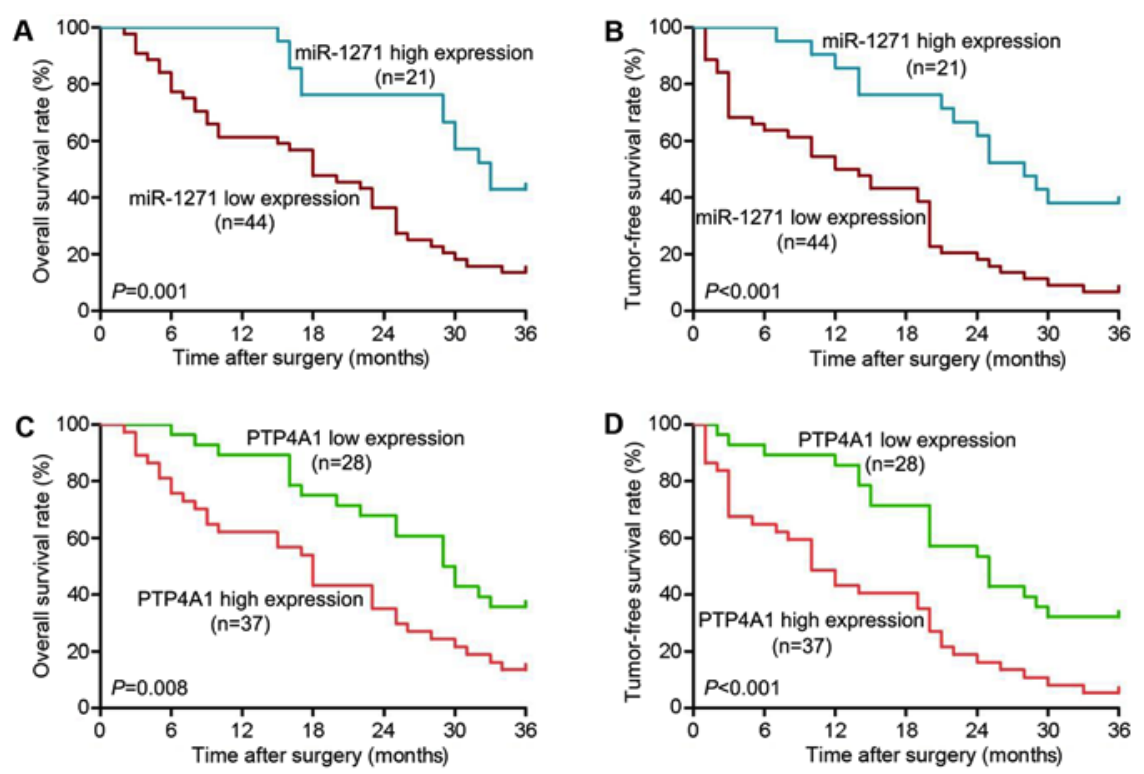

Figure 8. The prognostic significance of miR-1271 and PTP4A1 for HCC patients was evaluated by Kaplan-Meier analysis. The patients in the miR-1271 low expression group had (A) a lower overall survival rate and (B) a shorter tumor-free survival time. Patients in the high PTP4A1 expression group had a worse (C) overall survival and (D) a tumor-free survival. 


\section{Discussion}

The dysregulation of miRNA expression is a common incident in the development and progression of human cancers, including HCC (20). In the present study, we investigated the role of miR-1271 in HCC and discovered the following: First, miR-1271 was identified as a downregulated miRNA in HCC samples and cell lines. This finding was still consistently observed in the 271 HCC tissues from the TCGA database. We then found that the $23 \mathrm{HCC}$ tissues from patients with metastasis expressed lower miR-1271 levels than other 42 HCC tissues. The intrahepatic and hematogenous metastasis of $\mathrm{HCC}$ attributed to the poor prognosis of patients with HCC. miRNAs have been recognized as important regulators of human cancer metastasis (21). Hence, in the present study, we analyzed our clinical data to discover that a low expression of miR-1271 was associated with tumor metastasis and a poor prognosis of patients with HCC. This prognostic value of miR-1271 in HCC was consistent with a previous result in neuroglioma (22). These results strongly indicated that miR-1271 is associated with tumor metastasis in HCC.

The biological functions of miR-1271 have been partly uncovered in other types of cancer. miR-1271 has been demonstrated to inhibit cell proliferation in oral squamous cell carcinoma (23) and to sensitize human gastric cancer cells to cisplatin treatment (24). In the present study, and to the best of our knowledge, we report for the first time that miR-1271 is a critical inhibitor of cell migration and invasion in HCC through gain- and loss-of-function experiments in vitro. Moreover, the overexpression of miR-1271 also suppressed the formation of lung metastatic clusters in mice. EMT is identified as loss of epithelial marker (E-cadherin) expression and an increase in mesenchymal marker (vimentin and $\mathrm{N}$-cadherin) expression (25). EMT is involved in numerous liver disease states, such as HBV or HCV-associated viral hepatitis, non-alcoholic fatty liver disease, liver fibrosis and HCC (26). These diseases present EMT in hepatocytes and cancer cells, leading to cell migration or invasion. Therefore, EMT has been recognized as a fundamental mechanism for HCC metastasis. In this study, we demonstrated that the overexpression of miR-1271 increased E-cadherin expression, and decreased N-cadherin and vimentin expression, whereas the inhibition of miR-1271 exerted the opposite effects. These findings suggest that miR-1271 has considerable potential for cancer therapy.

PTP4A1 (also known as phosphatase of regenerating liver 1) belongs to a subfamily of prenylated protein tyrosine phosphatases (PTPs) (27). Even the expression of PTP4A1 in human normal tissues has not been well characterized, Wang et al (28) found that the PTP4A1 mRNA levels were elevated in a number of tumor cell lines, including HeLa, SK-Lu-1 and several melanoma cell lines. Our results also showed that a high expression of PTP4A1 in HCC tissues was associated with lower overall survival and disease-free rates. Although the transcriptional regulation of PTP4A1 is not yet well understood, post-transcriptional regulation by miRNAs has been widely reported. PTP4A1 serves as a tumor suppressor target of miR-339-5p in colorectal (29), and miR-601 (30) and miR-944 (31) in breast cancer. In this study, PTP4A1 was demonstrated as an effective target of miR-1271 by the following evidence: First, miR-1271 only decreased luciferase activity in MHCC97-H cells carrying the wild-type 3'-UTR of PTP4A1. Second, miR-1271 overexpression decreased the mRNA and protein expression levels of PTP4A1 in MHCC97-H cells, whereas miR-1271 knockdown increased their expression levels in Hep3B cells. In addition, a negative correlation between miR-1271 and PTP4A1 protein expression was confirmed in 65 HCC tissue samples. Finally, altering PTP4A1 expression in HCC cells abrogated the effects induced by miR-1271. These results suggest that PTP4A1 is a downstream effector of miR-1271 functions in HCC.

The proto-oncogene, tyrosine-protein kinase Src (simply c-Src), has been linked to the PTP family. Liang et al $(32,33)$ revealed that PTP4A3 promoted proliferation and invasion by the reduction of C-terminal Src kinase (Csk), leading to a decrease in Src-Tyr527. However, in multiple myeloma cells, PTP4A3 has been demonstrated to activate Src by increasing the phosphorylation at Tyr416, but not by decreasing the phosphorylation at Tyr527 (34). In A549 lung cancer cells, the inhibition of PTP4A1 directly decreased c-Src expression (35). Intriguingly, there were no significant changes in total c-Src expression levels or its phosphorylation status by PTP4A2 knockdown (36). Src activation induces Snail and MMP-9 expression $(37,38)$. In this study, miR-1271 inhibited the phosphorylation of c-Src at Tyr416 (Y416), and Snail and MMP-9 expression. Moreover, PTP4A1 knockdown mimicked this function, whereas PTP4A1 overexpression abrogated it. Even though the detailed mechanisms underlying the activation of c-Src by PTP4A1 are not yet clear, it is unreasonable that PTP4A1 regulates Src activation directly. First, our result showed that PTP4A1, a phosphatase, increased c-Src phosphorylation at Y416. Second, Luo et al (39) were unable to obtain direct binding evidence by immunoprecipitation. These results indicate that miR-1271-mediated PTP4A1 inhibition deactivates c-Src through an indirect signaling pathway.

In conclusion, the present study demonstrates that the downregulation of miR-1271 in HCC tissues is associated with metastasis and a poor prognosis. miR-1271 is confirmed as a novel tumor metastasis and EMT inhibitor in HCC. The multiple anticancer functions of miR-1271 are attributed to the inhibition of the PTP4A1/c-Src signaling pathway. Taken together, our findings suggest that miR-1271 is a prospective therapeutic target for HCC.

\section{Acknowledgements}

The present study was supported by a grant from the National Natural Scientific Foundation of China (no. 81472247).

\section{References}

1. Chen W, Zheng R, Baade PD, Zhang S, Zeng H, Bray F, Jemal A, $\mathrm{Yu}$ XQ and He J: Cancer statistics in China, 2015. CA Cancer J Clin 66: 115-132, 2016.

2. Burkhart RA, Ronnekleiv-Kelly SM and Pawlik TM: Personalized therapy in hepatocellular carcinoma: Molecular markers of prognosis and therapeutic response. Surg Oncol 26: 138-145, 2017.

3. Li C, Miao R, Liu S, Wan Y, Zhang S, Deng Y, Bi J, Qu K, Zhang J and Liu C: Down-regulation of miR-146b-5p by long noncoding RNA MALAT1 in hepatocellular carcinoma promotes cancer growth and metastasis. Oncotarget 8: 28683-28695, 2017.

4. Carrington JC and Ambros V: Role of microRNAs in plant and animal development. Science 301: 336-338, 2003. 
5. Tu K, Li C, Zheng X, Yang W, Yao Y and Liu Q: Prognostic significance of miR-218 in human hepatocellular carcinoma and its role in cell growth. Oncol Rep 32: 1571-1577, 2014.

6. Yang X, Liang L, Zhang XF, Jia HL, Qin Y, Zhu XC, Gao XM, Qiao P, Zheng Y, Sheng YY, et al: MicroRNA-26a suppresses tumor growth and metastasis of human hepatocellular carcinoma by targeting interleukin-6-Stat3 pathway. Hepatology 58 $158-170,2013$

7. Shih TC, Tien YJ, Wen CJ, Yeh TS, Yu MC, Huang CH, Lee YS, Yen TC and Hsieh SY: MicroRNA-214 downregulation contributes to tumor angiogenesis by inducing secretion of the hepatoma-derived growth factor in human hepatoma. J Hepatol 57: 584-591, 2012.

8. Li DP, Fan J, Wu YJ, Xie YF, Zha JM and Zhou XM: MiR-155 up-regulated by TGF- $\beta$ promotes epithelial-mesenchymal transition, invasion and metastasis of human hepatocellular carcinoma cells in vitro. Am J Transl Res 9: 2956-2965, 2017.

9. Sakabe T, Azumi J, Umekita Y, Toriguchi K, Hatano E, Hirooka Y and Shiota G: Prognostic relevance of miR-137 in patients with hepatocellular carcinoma. Liver Int 37: 271-279, 2017.

10. von Felden J, Heim D, Schulze K, Krech T, Ewald F, Nashan B, Lohse AW and Wege H: High expression of micro RNA-135A in hepatocellular carcinoma is associated with recurrence within 12 months after resection. BMC Cancer 17: 60, 2017.

11. Li L, Qu YW and Li YP: Over-expression of miR-1271 inhibits endometrial cancer cells proliferation and induces cell apoptosis by targeting CDK1. Eur Rev Med Pharmacol Sci 21: 2816-2822, 2017.

12. Zhong J, Liu Y, Xu Q, Yu J and Zhang M: Inhibition of DIXDC1 by microRNA-1271 suppresses the proliferation and invasion of prostate cancer cells. Biochem Biophys Res Commun 484: 794-800, 2017

13. Xu Z, Huang $\mathrm{C}$ and Hao D: MicroRNA-1271 inhibits proliferation and promotes apoptosis of multiple myeloma cells through inhibiting smoothened-mediated Hedgehog signaling pathway. Oncol Rep 37: 1261-1269, 2017.

14. Liu X, Ma L, Rao Q, Mao Y, Xin Y, Xu H, Li C and Wang X: MiR-1271 inhibits ovarian cancer growth by targeting cyclin G1. Med Sci Monit 21: 3152-3158, 2015.

15. Liu H, Wang H, Liu X and Yu T: miR-1271 inhibits migration, invasion and epithelial-mesenchymal transition by targeting ZEB1 and TWIST1 in pancreatic cancer cells. Biochem Biophys Res Commun 472: 346-352, 2016.

16. Wang Y, Xu L and Jiang L: miR-1271 promotes non-small-cell lung cancer cell proliferation and invasion via targeting HOXA5. Biochem Biophys Res Commun 458: 714-719, 2015.

17. Santamaria PG, Moreno-Bueno G, Portillo F and Cano A: EMT: Present and future in clinical oncology. Mol Oncol 11: 718-738, 2017.

18. Jolly MK, Ware KE, Gilja S, Somarelli JA and Levine H: EMT and MET: Necessary or permissive for metastasis? Mol Oncol 11: 755-769, 2017.

19. Li C, Yang W, Zhang J, Zheng X, Yao Y, Tu K and Liu Q SREBP-1 has a prognostic role and contributes to invasion and metastasis in human hepatocellular carcinoma. Int J Mol Sci 15 7124-7138, 2014.

20. Rupaimoole R and Slack FJ: MicroRNA therapeutics: Towards a new era for the management of cancer and other diseases. Nat Rev Drug Discov 16: 203-222, 2017.

21. Guo Y, Bao Y and Yang W: Regulatory miRNAs in colorectal carcinogenesis and metastasis. Int J Mol Sci 18: 18, 2017.

22. Gong J, Wang ZX and Liu ZY: miRNA-1271 inhibits cell proliferation in neuroglioma by targeting fibronectin 1 . Mol Med Rep 16: 143-150, 2017.
23. Kong D, Zhang G, Ma $\mathrm{H}$ and Jiang G: miR-1271 inhibits OSCC cell growth and metastasis by targeting ALK. Neoplasma 62: 559-566, 2015.

24. Yang M, Shan X, Zhou X, Qiu T, Zhu W, Ding Y, Shu Y and Liu P: miR-1271 regulates cisplatin resistance of human gastric cancer cell lines by targeting IGF1R, IRS1, mTOR and BCL2. Anticancer Agents Med Chem 14: 884-891, 2014.

25. Chen T, You Y, Jiang H and Wang ZZ: Epithelial-mesenchymal transition (EMT): A biological process in the development, stem cell differentiation, and tumorigenesis. J Cell Physiol 232: 3261-3272, 2017

26. Serrano-Gomez SJ, Maziveyi M and Alahari SK: Regulation of epithelial-mesenchymal transition through epigenetic and posttranslational modifications. Mol Cancer 15: 18, 2016.

27. Bessette DC, Qiu D and Pallen CJ: PRL PTPs: Mediators and markers of cancer progression. Cancer Metastasis Rev 27: 231-252, 2008

28. Wang J, Kirby CE and Herbst R: The tyrosine phosphatase PRL-1 localizes to the endoplasmic reticulum and the mitotic spindle and is required for normal mitosis. J Biol Chem 277: 46659-46668, 2002

29. Zhou C, Liu G, Wang L, Lu Y, Yuan L, Zheng L, Chen F, Peng F and $\mathrm{Li} \mathrm{X}$ : MiR-339-5p regulates the growth, colony formation and metastasis of colorectal cancer cells by targeting PRL-1. PLoS One 8: e63142, 2013.

30. Hu JY, Yi W, Wei X, Zhang MY, Xu R, Zeng LS, Huang ZJ and Chen JS: miR-601 is a prognostic marker and suppresses cell growth and invasion by targeting PTP4A1 in breast cancer. Biomed Pharmacother 79: 247-253, 2016.

31. Flores-Pérez A, Marchat LA, Rodríguez-Cuevas S, Bautista VP, Fuentes-Mera L, Romero-Zamora D, Maciel-Dominguez A, de la Cruz OH, Fonseca-Sánchez M, Ruíz-García E, et al: Suppression of cell migration is promoted by miR-944 through targeting of SIAH1 and PTP4A1 in breast cancer cells. BMC Cancer 16: 379, 2016.

32. Liang F, Liang J, Wang WQ, Sun JP, Udho E and Zhang ZY: PRL3 promotes cell invasion and proliferation by downregulation of Csk leading to Src activation. J Biol Chem 282: 5413-5419, 2007.

33. Liang F, Luo Y, Dong Y, Walls CD, Liang J, Jiang HY, Sanford JR, Wek RC and Zhang ZY: Translational control of C-terminal Src kinase (Csk) expression by PRL3 phosphatase. J Biol Chem 283: 10339-10346, 2008.

34. Abdollahi P, Vandsemb EN, Hjort MA, Misund K, Holien T, Sponaas AM, Rø TB, Slørdahl TS and Børset M: Src Family kinases are regulated in multiple myeloma cells by phosphatase of regenerating liver-3. Mol Cancer Res 15: 69-77, 2017.

35. Achiwa $\mathrm{H}$ and Lazo JS: PRL-1 tyrosine phosphatase regulates c-Src levels, adherence, and invasion in human lung cancer cells. Cancer Res 67: 643-650, 2007.

36. Wang Y and Lazo JS: Metastasis-associated phosphatase PRL-2 regulates tumor cell migration and invasion. Oncogene 31: 818-827, 2012.

37. Liu X and Feng R: Inhibition of epithelial to mesenchymal transition in metastatic breast carcinoma cells by c-Src suppression. Acta Biochim Biophys Sin (Shanghai) 42: 496-501, 2010.

38. Mon NN, Senga T and Ito S: Interleukin-1 $\beta$ activates focal adhesion kinase and Src to induce matrix metalloproteinase-9 production and invasion of MCF-7 breast cancer cells. Oncol Lett 13: 955-960, 2017.

39. Luo Y, Liang F and Zhang ZY: PRL1 promotes cell migration and invasion by increasing MMP2 and MMP9 expression through Src and ERK1/2 pathways. Biochemistry 48: 1838-1846, 2009. 